\title{
Endoscopic Hemostasis of Nonvariceal Gastrointestinal Bleeding
}

\author{
Yoshihiro Inoue*, Yasuhisa Fujino, Makoto Onodera, Satoshi Kikuchi, Masayuki Sato, \\ Hisaho Sato, Masahiro Kojika, Shigeatsu Endo \\ Department of Critical Care Medicine, School of Medicine, Iwate Medical University, Morioka, Japan

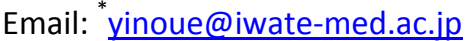

Received 23 August 2014; revised 15 September 2014; accepted 5 October 2014

Copyright (C) 2014 by authors and Scientific Research Publishing Inc.

This work is licensed under the Creative Commons Attribution International License (CC BY). http://creativecommons.org/licenses/by/4.0/

c) (7) Open Access

\begin{abstract}
We investigated 2668 patients with non-variceal upper gastrointestinal bleeding and 660 patients with lower gastrointestinal bleeding treated between 1987 and 2011 in our hospital. Upper gastrointestinal bleeding was associated with gastric ulcer, duodenal ulcer, Mallory-Weiss syndrome, esophageal disease, and others. Endoscopic hemostasis was performed in approximately $67 \%$ of all cases with upper gastrointestinal bleeding and approximately $90 \%$ of cases with ulcer. The hemostasis success rate was over $\mathbf{9 0 \%}$ for ulcer bleeding, and was also generally high for other diseases. The total number of patients with lower gastrointestinal bleeding was lower, with it being approximately $20 \%$ of those with upper gastrointestinal bleeding. Endoscopic hemostasis was performed in approximately $30 \%$ of the patients with lower gastrointestinal bleeding. The hemostasis success rate was generally high, but treatment switch to surgery or interventional radiology (IVR) was observed in some cases with colorectal diverticular bleeding.
\end{abstract}

\section{Keywords}

Gastrointestinal Bleeding, Endoscopic Hemostasis, Heater Probe Coagulation

\section{Introduction}

Endoscopic therapy has been the first line of treatment for upper gastrointestinal bleeding since the 1980s. Our hospital has adopted the endoscopic therapy since its establishment in November, 1980 up to the present. Endoscopic hemostasis of non-variceal upper gastrointestinal bleeding in our hospital used to be performed by local injections of hyper saline-epinephrine solution (HSE) [1] when we started. Then, microwave coagulation [2] was introduced in 1983, followed by adoption of heater probe coagulation (HP) [3] in 1986, which has been uti-

${ }^{*}$ Corresponding author.

How to cite this paper: Inoue, Y., Fujino, Y., Onodera, M., Kikuchi, S., Sato, M., Sato, H., Kojika, M. and Endo, S. (2014) Endoscopic Hemostasis of Nonvariceal Gastrointestinal Bleeding. International Journal of Clinical Medicine, 5, 1147-1154. 
lized until now. In addition, endoscopic diagnosis and therapy for lower gastrointestinal bleeding are being actively performed in the recent times. Thus, we reviewed endoscopic hemostasis of upper and lower gastrointestinal bleeding performed in our hospital from 1987 to 2011, for approximately 25 years.

\section{Material and Methods}

We investigated 2668 patients with non-variceal upper gastrointestinal bleeding and 660 patients with lower gastrointestinal bleeding treated between 1987 and 2011, a duration of approximately 25 years, in our hospital.

Upper gastrointestinal bleeding was associated with gastric ulcer (1152 patients), duodenal ulcer (483 patients), Mallory-Weiss syndrome (MWS) (285 patients), esophageal disease (274 patients), acute gastric mucosal lesion (AGML) (214 patients), malignant tumor (93 patients), stomal ulcer (69 patients), iatrogenic disease (55 patients), and others (43 patients) (Table 1 ).

Lower gastrointestinal bleeding was associated with colorectal diverticulum (113 patients), hemorrhoids (85 patients), ischemic colitis (80 patients), acute hemorrhagic rectal ulcer (AHRU) (75 patients), hemorrhagic colitis (57 patients), colorectal cancer (51 patients), iatrogenic disease (43 patients), and others (Table 2). The items investigated included the number of cases with endoscopic hemostasis, re-bleeding, hemostasis success, and/or death. Endoscopic hemostasis of non-variceal upper gastrointestinal bleeding was mostly performed by HP. In

Table 1. The cases of non-variceal upper gastrointestinal bleeding.

\begin{tabular}{cc}
\hline Disease & Cases (\%) \\
\hline Gastric ulcer & $1152(43.2)$ \\
Duodenal ulcer & $483(18.1)$ \\
Mallory-Weiss syndrome & $285(10.7)$ \\
Esophageal disease & $274(10.3)$ \\
AGML & $214(8.0)$ \\
Malignant tumor & $93(3.5)$ \\
Stomal ulcer & $69(2.6)$ \\
Iatrogenic disease & $55(2.0)$ \\
Others & $43(1.6)$ \\
Total & $2668(100)$ \\
\hline
\end{tabular}

AGML: acute gastric mucosal legion.

Table 2. The cases of lower gastrointestinal bleeding.

\begin{tabular}{cc}
\hline Disease & Cases (\%) \\
\hline Colorectal diverticulum & $113(17.1)$ \\
Hemorrhoid & $85(12.9)$ \\
Ischemic colitis & $80(12.1)$ \\
AHRU & $75(11.3)$ \\
Hemorrhagic colitis & $57(8.6)$ \\
Colonic cancer & $51(7.7)$ \\
Iatrogenic disease & $43(6.5)$ \\
Small intestinal disease & $38(5.8)$ \\
Colonic polyp & $36(5.5)$ \\
Colonic ulcer & $34(5.2)$ \\
Others & $48(7.3)$ \\
Total & $660(100)$ \\
\hline
\end{tabular}

AHRU: acute hemorrhagic rectal ulcer. 
contrast, endoscopic hemostasis of lower gastrointestinal bleeding was mainly performed by HP for AHRU, polypectomy for polyp, endoscopic hemorrhoidal ligation (EHL) or endoscopic injection sclerotherapy for hemorrhoid, and clipping for other bleeding.

Our hospital is an advanced critical care and emergency center that treats severe cases on a 24-hour basis. Patients with gastrointestinal bleeding are not the exception in our 24-hour medical care. When a patient with gastrointestinal bleeding is brought to our hospital after office hours, an outpatient physician provides initial treatment, and calls a full-time gastroenterological endoscopy physician, who takes over the patient's care on arrival. After preparation for endoscopy, the full-time physician carries out an endoscopic examination and treatment; then intravenously administers a proton pump inhibitor (PPI) if ulcer is detected. In case of upper gastrointestinal bleeding, second-look endoscopy is performed on Day 2 of admission, and additional treatment is provided if necessary. If serious underlying disease or complications are absent, oral feeds will be started following completion of the second-look endoscopy. For patients with ulcer bleeding, PPI will be orally administered. If no re-bleeding is observed, even patients with ulcer bleeding will be discharged approximately within a week. Four full-time gastroenterological endoscopy physicians attending our hospital are all certified by the Japan Gastroenterological Endoscopy Society, and three of them are qualified supervisors.

\section{Results}

Figure 1 and Figure 2 show the annual trends of the number of patients with upper gastrointestinal bleeding and those with gastric and duodenal ulcer bleeding, respectively. The number of both groups of patients gradually increased up to around the year 2000 and gradually decreased afterward. Endoscopic hemostasis was performed in 1763 of 2625 patients (67.2\%), excluding 43 patients with "other" diseases. These 1763 patients were composed of 1026 patients with gastric ulcer (90.6\%); 432 patients with duodenal ulcer (89.4\%); 118 patients with MWS (41.4\%); 60 patients with stomal ulcer (86.9\%); 50 patients with iatrogenic disease (90.9\%); 36 patients with malignant tumor (38.7\%); 27 patients with esophageal disease, such as esophageal inflammation and esophageal ulcer (9.9\%); and 14 patients with AGML (6.5\%) (Table 3). Table 4 shows the classification of ulcer bleeding and the hemostasis success rate. The hemostasis success rate is defined as the proportion of patients who achieve endoscopic hemostasis regardless of the presence/absence of re-bleeding. The hemostasis rate exceeded $90 \%$ in all the bleeding types according to the Forrest Classification [4]; e.g. 99.7\% of patients with gastric ulcer and $94.0 \%$ of patients with duodenal ulcer. Since 1995, no patients with gastric ulcer has undergone treatment conversion to surgery or IVR, etc., for uncontrolled bleeding. Table 5 shows the re-bleeding rate in

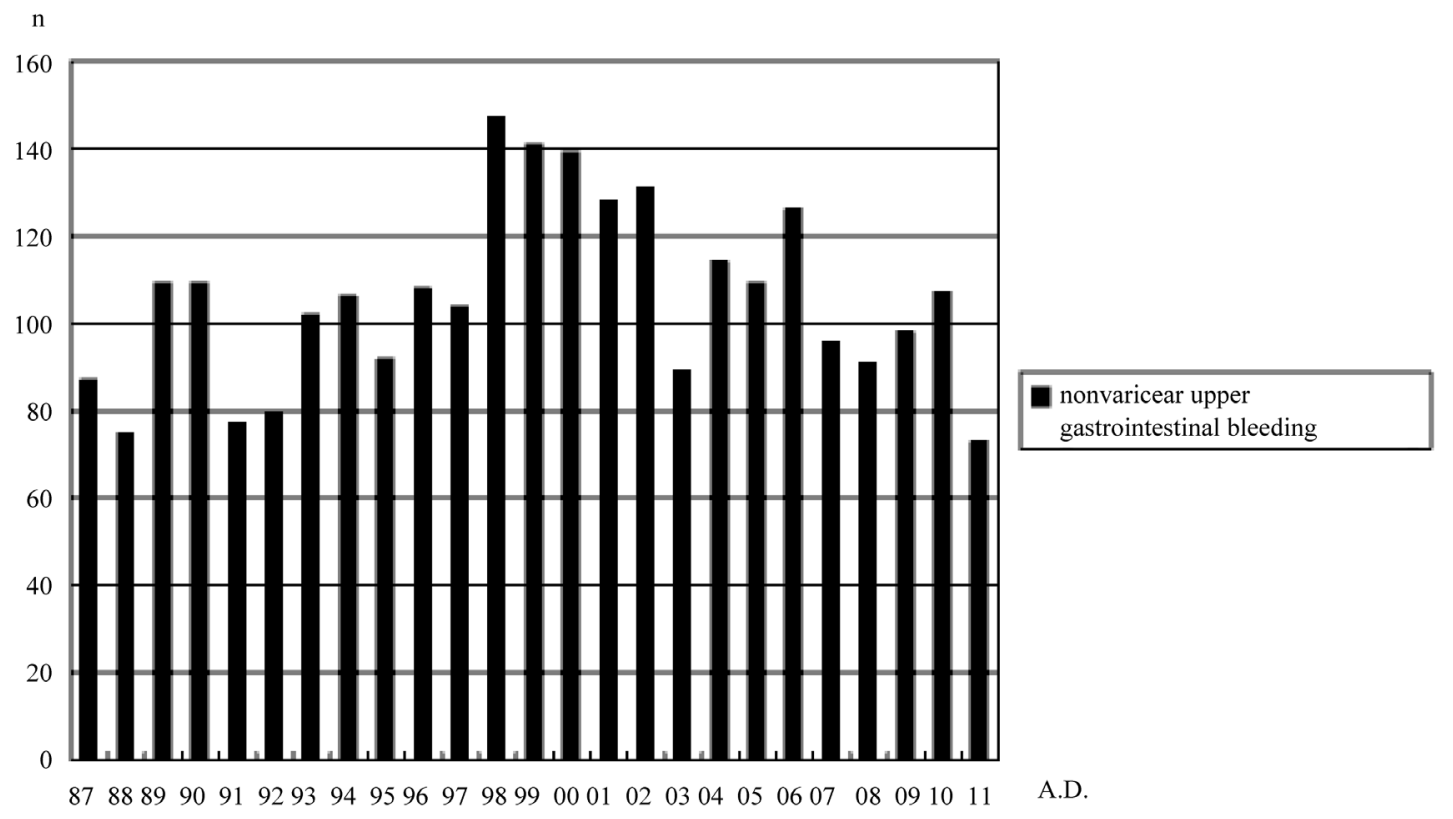

Figure 1. The cases of nonvaricear upper gastrointestinal bleeding from A.D. 1987 to 2011. 


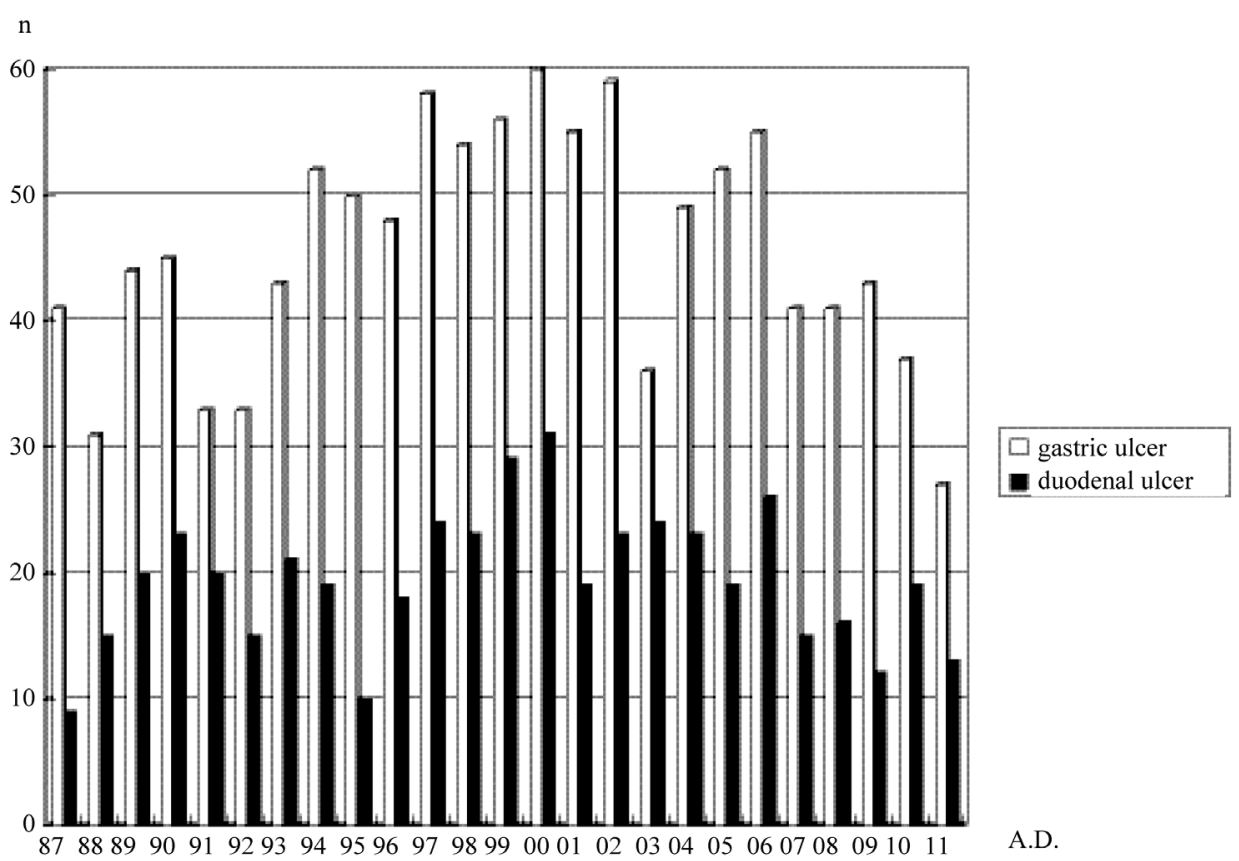

Figure 2. The cases of gastroduodenal ulcer from A.D. 1987 to 2011.

Table 3. The cases of endoscopic hemostasis for upper gastrointestinal bleeding.

\begin{tabular}{cc}
\hline Disease & Hemostatic cases/total cases (\%) \\
\hline Gastric ulcer & $1026 / 1152(90.6)$ \\
Duodenal ulcer & $432 / 483(89.4)$ \\
MWS & $118 / 285(41.4)$ \\
Stomal ulcer & $60 / 69(86.9)$ \\
Iatrogenic disease & $50 / 55(90.9)$ \\
Malignant tumor & $36 / 93(38.7)$ \\
Esophageal disease & $27 / 274(9.9)$ \\
AGML & $14 / 214(6.5)$ \\
Total & $1763 / 2625(67.2)$ \\
\hline
\end{tabular}

AGML: acute gastric mucosal legion.

Table 4. The successful cases of endoscopic hemostasis with forrest classification.

\begin{tabular}{cccc}
\hline \multirow{2}{*}{ Forrest classification } & \multicolumn{3}{c}{ Successful cases/total cases (\%) } \\
\cline { 2 - 4 } Ia & Gastric ulcer (\%) & Duodenal ulcer (\%) & Total (\%) \\
\hline Ib & $185 / 188(98.4)$ & $56 / 77(72.7)$ & $241 / 265(90.9)$ \\
IIa & $114 / 114(100)$ & $83 / 84(98.8)$ & $198 / 197(99.5)$ \\
IIb & $665 / 665(100)$ & $209 / 213(98.1)$ & $874 / 878(99.5)$ \\
Total & $59 / 59(100)$ & $58 / 58(100)$ & $117 / 117(100)$ \\
& $1023 / 1026(99.7)$ & $406 / 432(94.0)$ & $1429 / 1458(98.0)$ \\
\hline
\end{tabular}

Table 5. The rebleeding cases after endoscopic hemostasis.

\begin{tabular}{cc}
\hline Disease & Rebleeding cases/total cases (\%) \\
\hline Gastric ulcer & $70 / 1026(6.8)$ \\
Duodenal ulcer & $33 / 432(7.6)$ \\
Total & $103 / 1458(7.1)$ \\
\hline
\end{tabular}


ulcer patients. Re-bleeding occurred in $6.8 \%$ and $7.6 \%$ of patients with gastric ulcer and duodenal ulcer, respectively. Table 6 shows the death rate in patients with ulcer bleeding. Death occurred in 1.9\% and $4.4 \%$ of patients with gastric ulcer and duodenal ulcer, respectively. The main cause of death was multiple organ failure after endoscopic therapy.

Endoscopic hemostasis was performed in 118 of 285 patients with MWS. Re-bleeding occurred in six patients, for whom repeated endoscopic hemostasis was successfully achieved. Death occurred in two patients with hepatic cirrhosis; the cause of death was hepatic failure in both patients.

Endoscopic hemostasis was performed in 60 of 69 patients with stomal ulcer. Re-bleeding occurred in seven patients, of whom surgery was performed in three patients. Death occurred in two patients.

Endoscopic hemostasis was performed in 36 of 93 patients with malignant tumor for bleeding. Uncontrolled bleeding occurred in four patients, for which surgery and trans-catheter embolization using IVR were performed in two patients each. Death occurred in six patients.

Endoscopic hemostasis was performed in 50 of 55 patients with iatrogenic disease for bleeding associated with endoscopic biopsy or treatment including endoscopic mucosal resection and endoscopic sub-mucosal dissection (ESD). Surgery was performed for uncontrolled bleeding following papillotomy. Re-bleeding occurred in two patients, for whom repeated endoscopic hemostasis was successfully achieved. No death occurred.

Figure 3 shows the annual trend of the number of patients with lower gastrointestinal bleeding. The number of these patients tended to increase, in contrast to the trend for upper gastrointestinal bleeding. Table 7 shows the number of patients who underwent endoscopic hemostasis for lower gastrointestinal bleeding.Endoscopic hemostasis was performed in 58 of 75 patients with AHRU. Re-bleeding occurred in 11 patients, for whom repeated endoscopic hemostasis was successfully achieved. Many of these patients had serious underlying disease, and death due to the underlying disease occurred in 14 patients.

Endoscopic hemostasis was performed in 39 of 43 patients with iatrogenic disease for bleeding at the anastomotic sites after polypectomy or after surgery. Re-bleeding or death did not occur.Polypectomy was performed in 29 of 36 patients with colorectal polyps. Re-bleeding or death did not occur.

Endoscopic hemostasis by clipping was performed in 26 of 113 patients with colorectal diverticulum. Uncontrolled bleeding occurred in seven patients; surgery and trans-catheter embolization using IVR were performed in three and four patients, respectively. No death occurred.

EHL and endoscopic injection sclerotherapy were performed in 20 and three of 85 patients with hemorrhoids,

Table 6. The dead cases after endoscopic hemostasis.

\begin{tabular}{cc}
\hline Disease & Dead cases/total cases (\%) \\
\hline Gastric ulcer & $19 / 1026(1.9)$ \\
Duodenal ulcer & $19 / 432(6.0)$ \\
Total & $38 / 1458(2.6)$ \\
\hline
\end{tabular}

Table 7. The cases of endoscopic hemostasis for lower gastrointestinal bleeding.

\begin{tabular}{cc}
\hline Disease hemostatic cases & Total cases (\%) \\
\hline AHRU & $58 / 75(77.3)$ \\
Iatrogenic disease & $39 / 43(90.7)$ \\
Colonic polyp & $29 / 36(80.6)$ \\
Colorectal diverticulum & $26 / 113(23.0)$ \\
Hemorrhoid & $20 / 85(23.5)$ \\
Colonic ulcer & $18 / 34(52.9)$ \\
Small intestinal disease & $8 / 38(22.9)$ \\
Others & $6 / 48(12.5)$ \\
Total & $204 / 660(30.9)$ \\
\hline
\end{tabular}

AHRU: acute hemorrhagic rectal ulcer. 


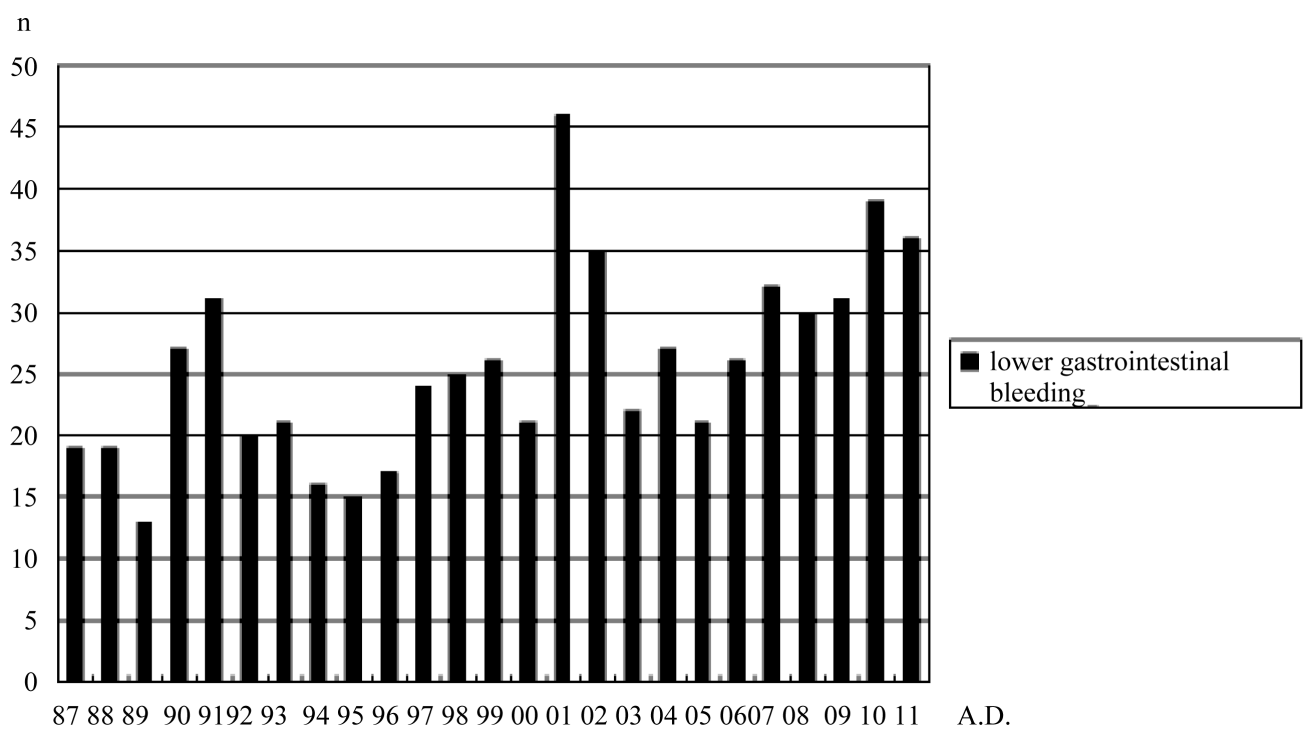

Figure 3. The cases of lower gastrointestinal bleeding from A.D. 1987 to 2011.

respectively. Although hemostasis was obtained temporarily, bleeding occurred recurrently in two patients under endoscopic injection sclerotherapy; both patients died eventually.

\section{Discussion}

Endoscopic hemostasis of non-variceal upper gastrointestinal bleeding in our hospital used to be performed by local injection of HSE when we started. Then, microwave coagulation was introduced in 1983, followed by adoption of HP in 1986, which has been utilized until now. Endoscopic hemostasis of non-variceal bleeding includes local injection therapy using HSE or ethanol [5], thermo-coagulation therapy using high frequency waves [6], HP or microwaves, etc., and mechanical grasping methods using clips [7] or indwelling snares, etc. Our hospital exclusively adopts thermo-coagulation therapy with HP because of its convenient procedures as follows: First, thermo-coagulation is attained by simple contact of the bleeding site with the probe tip; thus, tangential lesions can be treated without difficulty. Second, the probe sprays water; thus, the bleeding site can be easily identified. Third, thermo-coagulation and water delivery are controlled by footswitches; thus, hemostasis can be managed by one operator. Finally, the amounts of heat and water delivery are adjusted in a stepwise manner; thus, a wide variety of bleeding patterns from arterial bleeding to capillary bleeding can be treated [8]. Clipping hemostasis is not effective in some cases for treatment of tangential lesions, and it is not suitable for blood spurts from the capillary vessels. Local injection hemostasis or clipping hemostasis requires not only an endoscope operator but also assistant(s) who manipulate(s) an injection needle(s) or clip(s). Endoscopes integrated with water delivery function were recently developed; however before that, water delivery and treatment had not been available in one route at the same time. By resolving these difficulties, HP makes it possible to control hemostasis in an easier manner compared to the other treatment methods. Note that hemostatic forceps using highfrequency waves are also being actively performed; this method utilizes soft coagulation that is used for hemostasis during ESD [9] [10].

The hemostatic rate of gastric ulcer with HP was $99.7 \%$ and duodenal ulcer was $94.0 \%$. The hemostatic rate with other hemostatic methods were as follows: "clipping, 95.0\% [11]; pure ethanol injection, 92.0\% [12]; HSE injection, 95.0\% [13]; high frequency waves, 91.6\% [14]; and microwaves, 95.0\% [15].”

Second-look endoscopy is endoscopy performed within approximately 24 hours after endoscopic hemostasis for upper gastrointestinal bleeding [16]. If the second-look endoscopy is performed without fail and additional treatment is given as required, the incidence of re-bleeding can be decreased [17] [18], which eventually will improve the hemostasis success rate [19]. The second-look endoscopy is currently recommended for patients with increased bleeding risk [20]; this is highly likely due to involvement of cost-effectiveness. Gastrointestinal endoscopy and treatment costs in Japan are several times less in comparison with those in Europe and the United States; therefore, the repeated endoscopy and treatment are more cost-effective in Japan than those in the regions. 
In addition, in order to maintain the high hemostasis success rate, more patients must undergo second-look endoscopy in an effort to decrease re-bleeding as much as possible.

In our hospital, over a long period of time, hemostasis of gastric ulcer bleeding has been accomplished only by using an endoscopic method. The possible reasons for our success include the following factors: First, operators for endoscopic hemostasis have been settled in the long term in our hospital. Out of the four full-time gastroenterological endoscopy physicians, one has been attending our hospital for over 25 years, two for over 15 years, and one for over 8 years. Long-term engagement in medical care in a single hospital leads to the accumulation of expertise and treatment skills, which is believed to be reflected in treatment outcomes. Second, thermo-coagulation therapy by HP is adopted as an exclusive method for hemostasis in our hospital. Not surprisingly as the situation requires, clipping, HSE injection therapy, or pure ethanol injection therapy may be performed, but utilization of HP is our basic stance. As described above, HP is easy-to-use as a hemostasis procedure, and it is expected that being expert in a uniform treatment will improve the outcomes. Third, second-look endoscopy is actively performed in our hospital. After emergency treatment for ulcers including that for the treatment of varices and MWS, second-look endoscopy is actively performed and additional treatment is provided if necessary. As described above, these tactics is effective not only for reduction in re-bleeding but also for improvement in treatment outcomes.

The incidence of lower gastrointestinal bleeding is $8 \%-10 \%$, lower than that of upper gastrointestinal bleeding [21]. Gastrointestinal endoscopy is useful for identification of the source of bleeding; however, the anatomical forms of the colon (with acute angles of flexions and haustra) can make it difficult to identify the source. Although small-intestinal endoscopy for small-intestinal bleeding is routinely performed at present, this method is not indicated for emergency treatment under some circumstances [22]; thus, other measures such as CT and angiography are often taken. Only few diseases are subject to endoscopic hemostasis; in addition, the thin intestinal wall often prevents thermo-coagulation therapy and ethanol injection therapy, which may cause strong tissue damage, from being chosen as hemostasis procedures. Instead, clipping is generally used for these cases [23]. The main target diseases for hemostasis include colorectal diverticulum, rectal ulcers, polyps, iatrogenic diseases, and hemorrhoids. AHRU is an irregular-shaped ulcer formed immediately above the dentate line of the anus, and it is accompanied by painless, acute massive bleeding in elderly patients with severe underlying disease. Endoscopic hemostasis is appropriate for the disease and thermo-coagulation avails against bleeding. Bleeding from polyp usually resolves spontaneously, and elective polypectomy is performed. Iatrogenic disease is effectively managed by hemostasis using clips. Diverticular bleeding usually resolves spontaneously, but bleeding persists in some cases and requires endoscopic hemostasis using clips. In the event that the bleeding point is not accurately clipped, embolization may be performed under angiographic guidance. Hemorrhoidal bleeding usually resolves spontaneously; however, when bleeding persists, EHL may be performed. In cases when endoscopic hemostasis does not succeed or endoscopy fails to identify the source of bleeding, etc., IVR with lower invasiveness is selected by an increasing number of hospitals rather than emergency surgery [24].

\section{Conclusion}

We reported the current state of endoscopic therapy for gastrointestinal bleeding in our hospital. Endoscopic diagnosis and therapy are superior for treatment of upper gastrointestinal bleeding with no treatment switch in most cases; however, massive duodenal bleeding may require treatment conversion to IVR in some cases. Endoscopic diagnosis and therapy are also effective for lower gastrointestinal bleeding; nevertheless, surgery or IVR is chosen in more cases compared to upper gastrointestinal bleeding. If small-intestinal endoscopy is further performed on a routine basis, it is expected that the number of cases treated by endoscopic therapy will increase in the future.

\section{Acknowledgements}

The authors declare no conflict of interest. Part of the article was presented at a symposium in the 48th Annual Congress of Japanese Society for Abdominal Emergency Medicine in 2012.

\section{References}

[1] Hirao, M., Yamazaki, H., Masuda, K., Kobayashi, T., Yamaguchi, S., Kawachi, H. and Sato, F. (1980) Hyper SalineEpinephrine Solution Injection Therapy. Stomach and Intestine, 15, 751-755. 
[2] Tabuse, K., Katsumi, S., Kobayashi, Y., Nagai, Y., Noguchi, H. and Aoyama, O. (1982) Endoscopic Microwave-Tissue-Coagulation Method. Gastroenterological Endoscopy, 24, 1526-1535.

[3] Protell, R.L., Rubin, C.E., Auth, D.C., Silverstein, F.E., Terou, F., Dennis, M. and Piercey, J.R. (1978) The Heater Probe: A New Endoscopic Method for Stopping Massive Gastrointestinal Bleeding. Gastroenterology, 74, $257-262$.

[4] Forrest, J.A., Finlayson, N.D. and Shearman, D.J. (1974) Endoscopy in Gastrointestinal Bleeding. Lancet, 2, $394-397$. http://dx.doi.org/10.1016/S0140-6736(74)91770-X

[5] Asaki, S., Nishimura, T., Iwai, S., Kitamura, T., Masuda, Y., Hazama, K., Sato, M., Shibuki, S., Hanzawa, K., Sato, A., Ohkata, T. and Goto, Y. (1981) Tissue Solidification in Coping with Digestive Tract Bleeding: Hemostatic Effect of Local Injection of 99.5\% Ethanol. Gastroenterological Endoscopy, 23, 792-799.

[6] Maruyama, M. (1992) Endoscopic Electrocoagulation Therapy. Endoscopia Digestiva, 4, 911-917.

[7] Hachisu, T., Yamada, H. and Sato, S. (1996) The Knack of Clipping Hemostasis. Endoscopia Digestiva, 8, $1205-1207$.

[8] Inoue, Y., Fujino, Y. and Onodera, M. (2002) Heater Probe Method. In: Kitajima, M., Ed., The New Treatment of Gastroenterological Endoscopy, The Institution of Advanced Medicine, Tokyo, 57-61.

[9] Sugiyama, T., Dozaiku, T., Toyonaga, T., Hirooka, T., Ueda, C., Iwata, Y., Ono, W., Sugiyama, R. and Hirooka, T. (2006) The Usefulness of $4+1$ Contact Method Using Soft Coagulation for Bleeding Gastric Ulcers. Gastroenterological Endoscopy, 48, 204-211.

[10] Oyama, T., Miyata, Y., Tomori, A., Hotta, K., Yoneminato, T. and Morita, C. (2004) Selecting the Method of a High Frequency Unit for Endoscopic Submucosal Dissection. Endoscopia Digestiva, 16, 723-724.

[11] Nagayama, K., Tazawa, J., Sakai, Y., Miyasaka, Y., Yu, S.H., et al. (1999) Efficacy of Endoscopic Clipping for Bleeding Gastroduodenal Ulcer: Comparison with Topical Ethanol Injection. American Journal of Gastroenterology, 94, 2897-2901. http://dx.doi.org/10.1111/j.1572-0241.1999.01455.xb

[12] Nishiaki, M., Tada, M., Yanai, H., Tokiyama, H., Nakamura, H. and Okita, K. (2000) Endoscopic Hemostasis for Bleeding Peptic Ulcer Using a Hemostatic Clip or Pure Ethanol Injection. Hepato-Gastroenterology, 47, 1042-1044.

[13] Hirao, M., Imai, Y. and Yamaguchi, S. (1997) Hyper Saline-Epinephrine Solution Injection Therapy. In: Saigenji, K., Ed., Endoscopic Handbook for Gastrointestinal Hemorrhage, Chugai Medical Co., Tokyo, 132-138.

[14] Maruyama, M. (1992) Endoscopic Electrocoagulation Therapy. Endoscopia Digestiva, 4, 911-917.

[15] Nagai, Y., Takifuji, K., Shioji, Y., Ota, K., Hamanaka, H., Funabiki, S. and Tanimura, H. (2000) Endoscopic Microwave Coagulation Therapy. Endoscopia Digestiva, 12, 770-771.

[16] Inoue, Y., Fujino, Y. and Onodera, M. (2012) Emergency Endoscopy for Upper Gastrointestinal and Non-Variceal Bleeding. Gastroenterology, 55, 545-552.

[17] Chiu, P.W., Lam, C.Y., Lee, S.W., Kwong, K.H., Lam, S.H., Lee, D.T. and Kwok, S.P. (2003) Effect of Scheduled Second Therapeutic Endoscopy on Peptic Ulcer Re-Bleeding: A Prospective Randomized Trial. Gut, 52, 1403-1407. http://dx.doi.org/10.1136/gut.52.10.1403

[18] Marmo, R., Rotondano, G., Bianco, M.A., Piscopo, R., Piscopo, A. and Cipolletta, L. (2003) Outcome of Endoscopic Treatment for Peptic Ulcer Bleeding: Is a Second Look Necessary? A Meta-Analysis. Gastroenterological Endoscopy, 57, 62-67. http://dx.doi.org/10.1067/mge.2003.48

[19] Yamaguchi, A., Uchizono, H., Taniguchi, Y., Iwakiri, Y., Utsunomiya, T., Shimokawara, H., Fujita, H., Nagota, T. and Ito, T. (2002) Internal Medical Treatment of Upper Gastrointestinal Hemorrhage. Japanese Journal of Clinical Internal Medicine, 17, 28-34.

[20] Bakun, A.N., Bardou, M., Kuipers, E.J., Sung, J., Hunt, R.H., Martel, M. and Sinclair, P. (2010) International Consensus Recommendations on the Management of Patients with Nonvariceal Upper Gastrointestinal Bleeding. Annual of Internal Medicine, 152, 101-113. http://dx.doi.org/10.7326/0003-4819-152-2-201001190-00009

[21] Inoue, Y., Kikuchi, S., Onodera, M., Fujino, Y., Kojika, M., Sato, N. and Endo, S. (2007) Primary Disease and Endoscopic Hemostasis of the Lower Digestive Tract Hemorrhage. Journal of Abdominal Emergency Medicine, 27, 923-928.

[22] Abe, T., Mizutani, M., Kawai, N., Kawano, J. and Sato, N. (2007) Double Balloon Enteroscopy for Diagnosis and Treatment of Small Intestinal Hemorrhage. Journal of Abdominal Emergency Medicine, 27, 949-956.

[23] Sugiyama, H. (2007) Endoscopic Hemostasis and Interventional Radiology for Lower Gastrointestinal Bleeding. Journal of Abdominal Emergency Medicine, 27, 929-935.

[24] Suzuki, S., Harada, N., Hayashi, T. and Suzuki, M. (2007) Selection of Non-Operative Hemostatic Therapeutic Strategies for Lower Gastrointestinal Bleeding. Journal of Abdominal Emergency Medicine, 27, 937-940. 
Scientific Research Publishing (SCIRP) is one of the largest Open Access journal publishers. It is currently publishing more than 200 open access, online, peer-reviewed journals covering a wide range of academic disciplines. SCIRP serves the worldwide academic communities and contributes to the progress and application of science with its publication.

Other selected journals from SCIRP are listed as below. Submit your manuscript to us via either submit@scirp.org or Online Submission Portal.
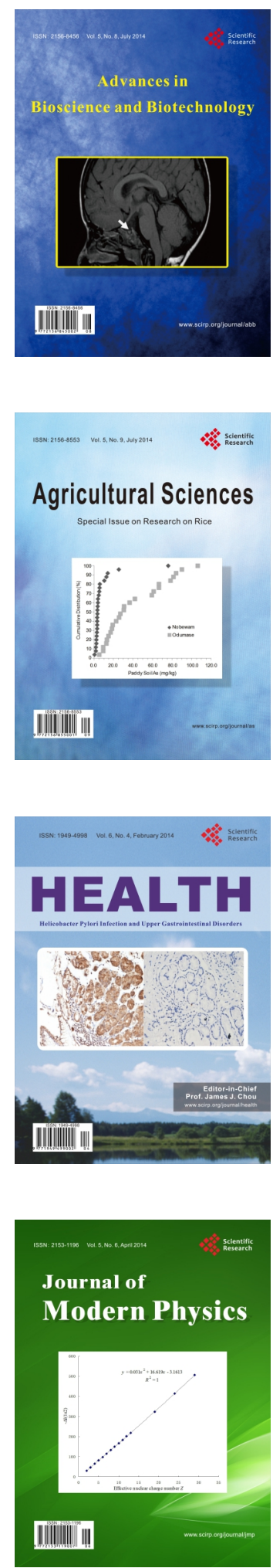
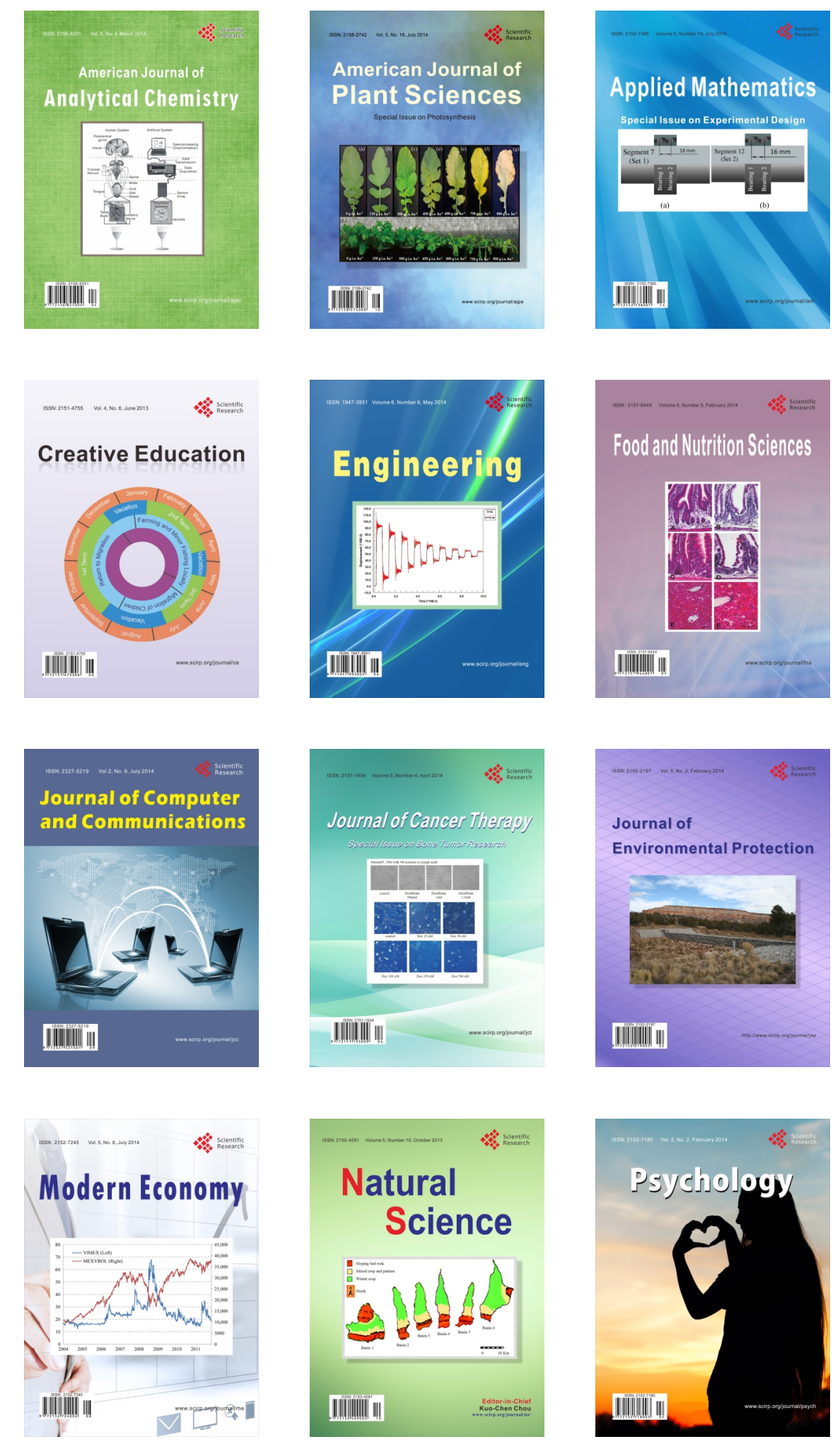